\title{
Water Storage Instead of Energy Storage for Desalination Powered by Renewable Energy-King Island Case Study
}

\author{
Aya Tafech, Dia Milani * and Ali Abbas* \\ School of Chemical and Biomolecular Engineering, the Univeristy of Sydney, Sydney, NSW 2006, Australia; \\ ataf7921@uni.sydney.edu.au \\ * Correspondences: dia.milani@sydney.edu.au (D.M.); ali.abbas@sydney.edu.au (A.A.); \\ Tel.: +61-2-9351-3714 (D.M.); +61-2-9351-3002 (A.A.); Fax: +61-2-9351-2854 (D.M. \& A.A.)
}

Academic Editor: Moran Wang

Received: 31 August 2016; Accepted: 11 October 2016; Published: 19 October 2016

\begin{abstract}
In this paper, we scrutinized the energy storage options used in mitigation of the intermittent nature of renewable energy resources for desalination process. In off-grid islands and remote areas, renewable energy is often combined with appropriate energy storage technologies (ESTs) to provide a consistent and reliable electric power source. We demonstrated that in developing a renewable energy scheme for desalination purposes, product (water) storage is a more reliable and techno-economic solution. For a King Island (Southeast Australia) case-study, electric power production from renewable energy sources was sized under transient conditions to meet the dynamic demand of freshwater throughout the year. Among four proposed scenarios, we found the most economic option by sizing a $13 \mathrm{MW}$ solar photovoltaic (PV) field to instantly run a proportional RO desalination plant and generate immediate freshwater in diurnal times without the need for energy storage. The excess generated water was stored in $4 \times 50 \mathrm{ML}$ (mega liter) storage tanks to meet the load in those solar deficit times. It was also demonstrated that integrating well-sized solar PV with wind power production shows more consistent energy/water profiles that harmonize the transient nature of energy sources with the water consumption dynamics, but that would have trivial economic penalties caused by larger desalination and water storage capacities.
\end{abstract}

Keywords: energy storage; water storage; off-grid desalination; King Island; transient conditions

\section{Introduction}

Global energy markets are rapidly changing. Renewable energy technologies now constitute more than half of the new power plants built worldwide each year [1]. Unlike hydro and geothermal renewable energy sources which show readily stable forms of energy over time, other renewable energy sources cannot be stockpiled and must be used when available or be regarded as lost energy potentials. The major restraint for increasing the share of renewable energy sources is their intermittency, which can be addressed through energy storage when available and energy use when needed. Therefore, to bring renewable energy sources (e.g., solar and wind) to independence and reliability, adequate energy storage technologies (ESTs) must be deployed. The role of energy storage systems in integration with renewable energy sources is more evident in the remote and stranded regions where connecting to the nationwide electricity grid is cost prohibitive. Although the energy is mostly required in the form of electricity, for economic reasons it is possible to convert the electricity and store it in another form of energy which can then be converted back to electricity when needed [2]. There are a number of well-established and enormous developing technologies offering significant potentials to enable energy storage in integration with various renewable sources (Figure 1). Present ESTs can be 
loosely categorized as either mechanical, electrical, thermal, and chemical systems [3]. Each category contains several technologies for consideration as outlined in Figure 1. Up to the beginning of 21st century, the only viable energy storage option was in the form of pumped hydro storage that is only practicable at certain topographic conditions. Today, around 1600 energy storage projects at different scales with a total capacity of approximately $193 \mathrm{MW}$ are constructed worldwide (Figure 2) [4]. The feasibility of each energy storage application would highly depend on several factors including: the efficiency, energy capacity, energy density, run time, capital investment costs, response time, lifetime in years and cycles, self-discharge, and maturity of the technology. Flywheels, supercapacitors, and superconducting magnetics show the highest maximum efficiency, and fastest response times, however they have among the highest capital costs [3]. Pumped hydro storage systems have the highest capacity by a large margin, but are also among the least energy dense storage options. The storage technologies capable of providing continuous electricity supply for $24 \mathrm{~h}$ or more are underground compressed air energy storage, pumped hydro, fuel cells and high temperature thermal energy storage systems, However, they are expensive to place and build, with long construction time, and only suitable for large scale projects [5]. Batteries, overall, are widely used EST because they are clean, efficient, scalable, and can provide the stored energy instantaneously. However, they are relatively hindered by high costs, high rate of self-discharge, short lifecycle, and the presence of hazardous/toxic components in their assembly [5]. A life cycle assessment of batteries compatible with PV systems indicates that batteries are the most responsible for the environmental impacts, due to their relatively short lifespan and heavy metal content [6].

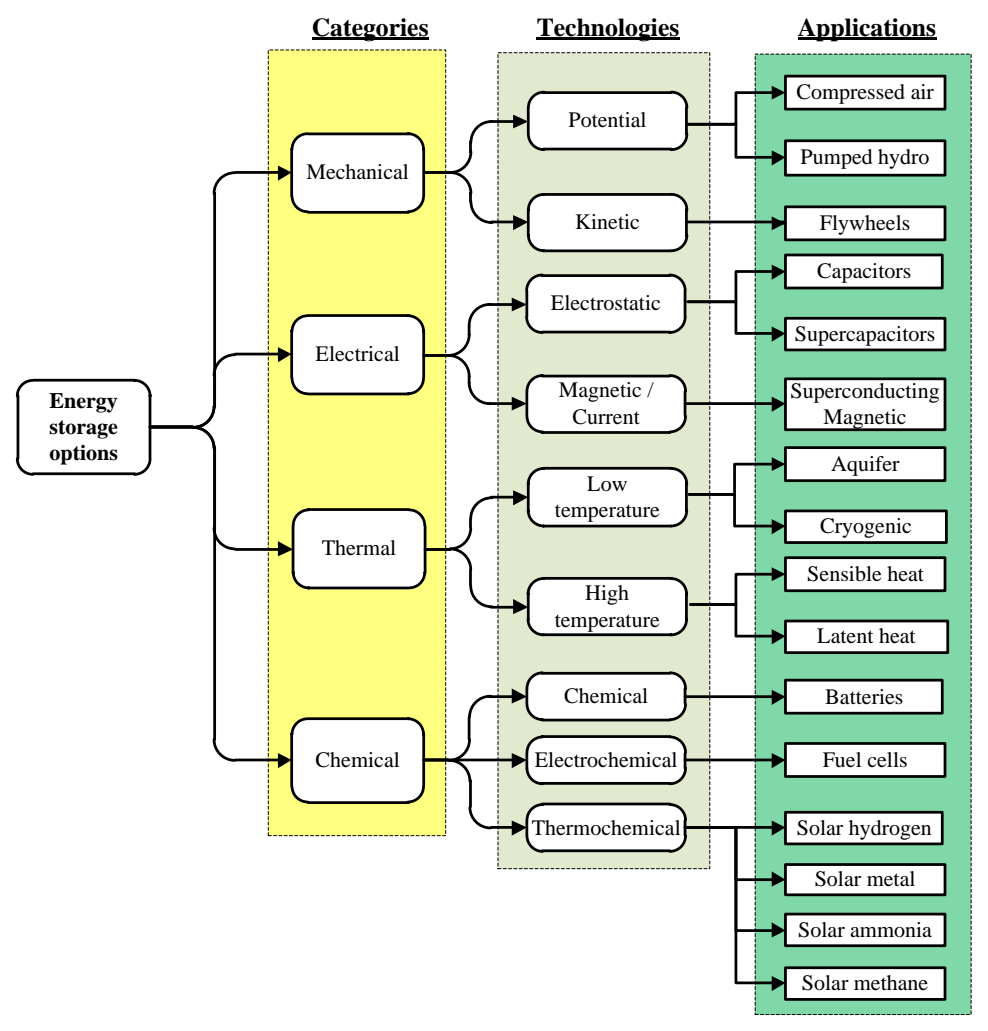

Figure 1. Categorization of energy storage options and applications.

The choice for the right EST(s) for a particular location would highly depend on many geographical, economic, social, and political factors as the applications of the available technologies involve significant investments and funding which often requires adequate regulatory support [7]. In this paper, we have highlighted the renewable energy and EST arrangements that are currently in place for the electric power supply in King Island (in Tasman Sea, Southeast Australia) and studied 
a similar energy portfolio for a reliable water supply to the residents of the island via a hypothetical desalination plant. We have argued that EST option is mainly relevant to the energy usage application, whereas for desalination purposes, this option is techno-economically unfeasible compared to "water storage options".

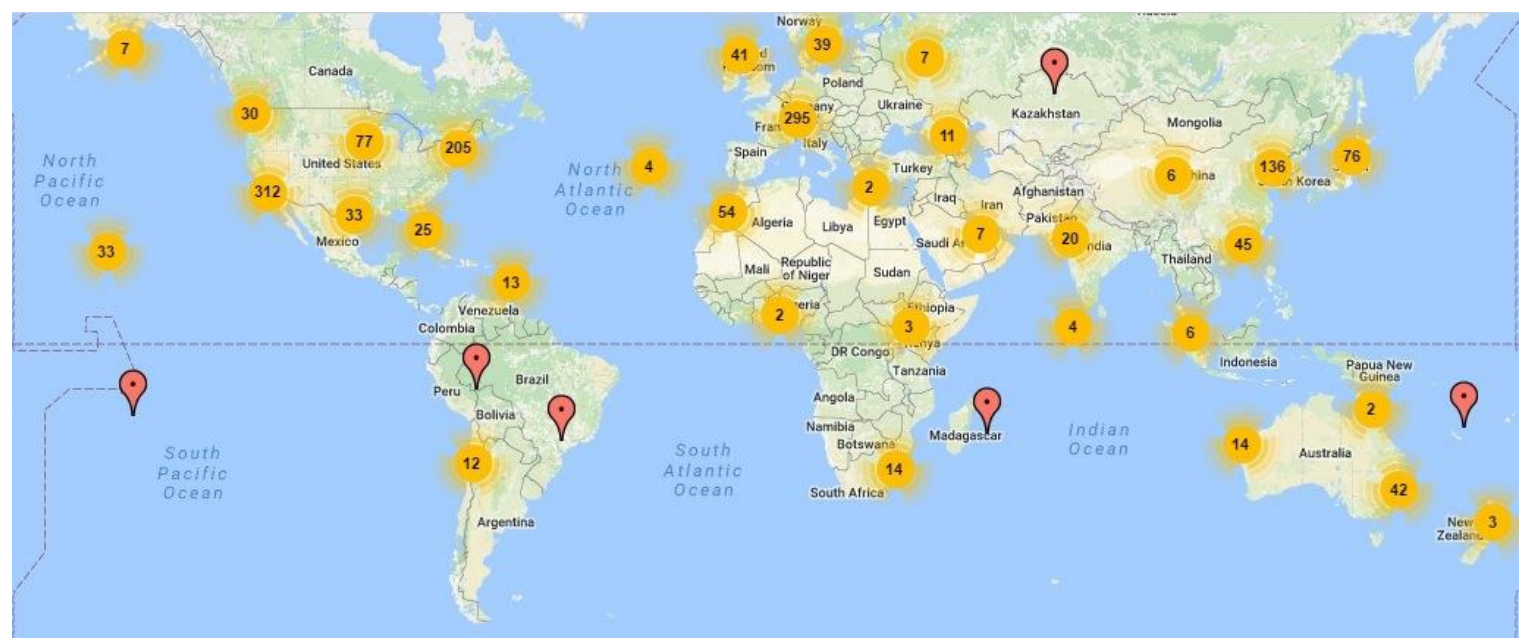

Figure 2. A worldwide snapshot of approximately 1600 energy storage projects with total capacity of $193 \mathrm{MW}$ as in August 2016 (adopted from DOE [4], with permission from STRATEGEN Consulting and Sandia, 2016).

\subsection{King Island Case Study}

King Island (Latitude 39.9 S, Longitude 144 E) is located at Tasmania's northwest, between Victoria and Tasmania (Figure 3A). The population of King Island is 1600 residents as in year 2014 [8], the majority are living in Currie. It is common for off-grid and remote communities like King Island to obtain electricity via conventional diesel generators. However in King Island, an innovative power system was developed to supply over $65 \%$ of King Island's energy needs using renewable energy, thereby reducing carbon dioxide emissions by more than 95\% [9]. This power system consists of a hybrid of solar, wind, and diesel/biodiesel power generators and a battery, fly wheel, and a resistor for energy storage. These power options are connected via a smart grid technology that helps match the island's energy needs with the available energy supply sources. The aim of this project is to allow the power system to rely less on diesel generation and provide a reliable and stable electricity supply while reducing carbon dioxide emissions. To increase community awareness/participation in the power generation/management portfolio of the island, a live data display is demonstrated online representing the proportion of power generation/storage/usage at every time step (Figure 3B).

King Island has a total area of $1098 \mathrm{~km}^{2}$, where $178 \mathrm{~m}^{2}$ of land is covered by water, mostly brackish. The groundwater quality is also poor due to extensive agricultural activities, poor vegetation management, and geographic reasons such as landform and climate patterns [10]. All of the above have led to elevated salt levels in water streams and comparatively reveal high nutrient levels than other rivers in Tasmania [10]. Importantly, the quantity and quality of freshwater have directly impacted the development and population growth on the island. Besides, King Island has a $145 \mathrm{~km}$ coastline and therefore easy access to seawater, solar, and wind resources. For example, westerly winds can reach over $100 \mathrm{~km} / \mathrm{h}$ [11]. Therefore, the potential of desalination can be realized in a sustainable concept of employing renewable technologies and eliminating excessive GHG emissions, which is a very important strategy for the future of this island. 


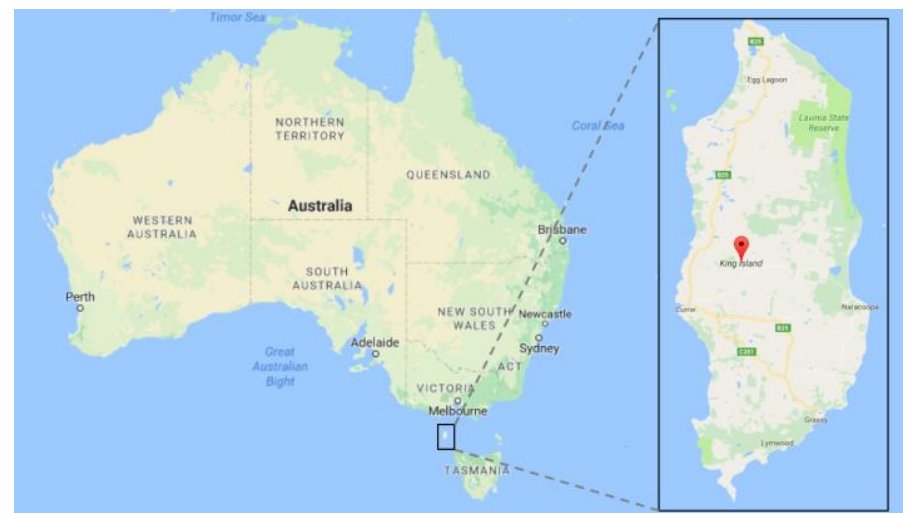

(A)

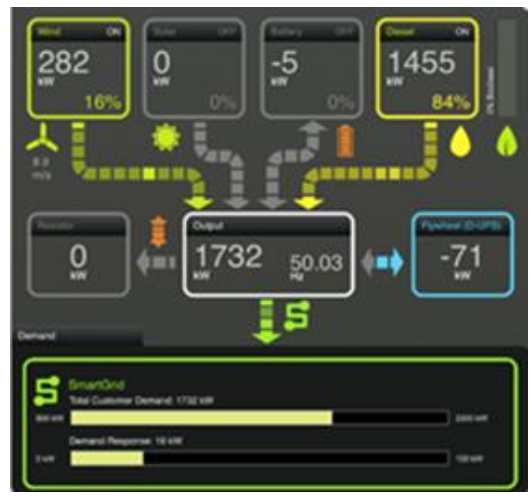

(B)

Figure 3. The location of King Island in Australia (A); and the current arrangement of hybrid energy portfolio set for the Island (B).

In this paper, we have proposed an off-grid desalination plant that generates adequate freshwater for the residents of King Island by forecasting the daily water demand for the next 25 years. We have developed a techno-economic model for three primary and two hybrid desalination technologies. The most economical model is integrated with renewable energy sources as a mean of power production. In this hybridization and under transient conditions, the annual performance of four proposed scenarios is analyzed. In the first scenario, a solar PV field is sized and optimized with a battery-set for energy storage, whereas in the other three scenarios the battery-set is eliminated. In the second scenario the desalination plant and solar PV field are oversized to generate instant and sufficient freshwater during the day and store access water in storage tanks for night usage. In the third and fourth scenarios, wind turbines are integrated in the energy portfolio for appropriate energy production in solar deficit times. We have proved that in integrating renewable energy with desalination process, energy storage is not a viable option and we have developed a scalable economic water storage option that is able to meet freshwater demand for the residents of King Island or similar case-studies.

\subsection{Process Description and Modelling}

This study utilizes two software programs, Desalination Economic Evaluation Program (DEEP) [12] and System Advisory Model (SAM) [13]. DEEP, developed by the International Atomic Energy Agency (IAEA), is an effective modelling instrument to evaluate various power and desalination cogeneration configurations and is suitable for comparison analysis among different desalination technologies. SAM, developed by the National Renewable Energy Laboratory (NREL), is a performance and finance modelling tool vigorous in providing the cost of energy estimates for grid-connected power projects based on installation and operating costs inputs and system design parameters.

The freshwater demand for the residents of King Island varies on a daily and seasonal basis while the population is increasing. We projected the total water demand and sized the desalination plant accordingly, while the energy input either from the solar field, wind turbines, or power storage has to satisfactorily meet the immediate load at all times. In DEEP, we developed three primary desalination models using well-established desalination technologies namely; multi-stage flash (MSF), multiple effect distillation (MED), and reverse osmosis (RO) [14-17]. In addition, we developed two desalination hybrid models; MSF + RO and MED + RO. In these five models, we assumed the electric power comes from the grid to eliminate the attached power plant and only counted for the capital cost (CAPEX) of the desalination plant. By selecting the most cost-effective desalination option, we entered the financial data for selected desalination plant as a single entity into SAM model. In SAM, we proposed four scenarios for energy production and storage: 
Scenario 1: The solar field is sized to provide instant power for desalination and also excess power is stored in designated batteries to meet the load in solar insufficient times.

Scenario 2: The solar field and desalination plant are sized to meet instant water demand and also produce excess water storable in designated water tanks to meet the load when the solar field is inactive.

Scenario 3: Cogenerated power from the solar field and a wind farm (two wind turbines) is optimized to meet the immediate load and store excess water in designated storage tanks for later use.

Scenario 4: Similar to Scenario 3, but optimized for larger wind farm (four wind turbines) and smaller size for solar field.

The cost components of the land value, desalination plants, solar PV field, wind turbines, batteries, water storage systems, including tax rates, incentives, debt terms and all financial parameters-are checked and updated accordingly.

\subsection{Desalination Options}

As of June 2015, there were 18,426 desalination plants established in 150 countries, producing more than 86.8 million cubic meters of pure water per day [18]. Traditional seawater desalination is climate independent and only limited by investment bounds and energy accessibilities. Desalination plants enjoy economies of scale in treatment facility construction. Large desalination plants built between 2000 and 2005 were typically designed to supply $5 \%-10 \%$ of the drinking water of coastal cities. More recently, regional or national seawater desalination projects in countries such as Spain, Australia, Algeria, and Singapore have been planned to supply $20 \%-50 \%$ of a city's long-term freshwater demand [19]. Other large cities in Gulf Corporation Countries (GCC) and the Middle East and North Africa (MENA) region are 100\% dependent on desalinated water [20]. Potential sites for large desalination plants need to meet specified criteria such as proximity to the ocean, access to a power source, and also minimal environmental impact [21]. There are three different key principles governing the desalination process briefly outlined below [22]:

(1) Phase Change Method: This process involves heating the feedwater to a certain point to generate steam, which passes through a condenser, thereby producing liquid water in the output. Since there is a phase change directly related to the heat input, this technology is more compatible with waste/low-grade heat, including solar thermal technologies. Mechanical vapor compression (MVC), thermal vapor compression (TVC), multi-effect distillation (MED), and multi-stage flash distillation (MSF) are partially/totally abided by this principle and highly compatible with solar thermal applications [14].

(2) Non-Phase Change Method: In this method, the feedwater remains in liquid phase and does not evaporate. The feedwater is pressurized on a selective barrier (membrane) to prevent the penetration of dissolved solids and impurities with the pure water. The required pressure is maintained by powerful pumps, often using electricity as a source of power. The main applications of this principle are Electro-dialysis (ED) and Reverse Osmosis (RO). Reverse Osmosis are modular and scalable units relatively efficient, less-expensive, and easy to replace [23]. The current worldwide market share is almost $33 \%$ for phase-change methods compared to $67 \%$ for non-phase change methods [24].

(3) Hybridization method: This refers to types of hybrid processes which combine two processes used for the desalination processes (e.g., RO + MED). In this way, the water quality can be improved in a substantial way by reducing the amount of the total dissolved salts present in the feed water. It is a thermo-membral process that is hybridizing both thermal and membrane distillation technologies to accurately blend and produce high quality water. This option is more viable in conjunction with the nearby power plant. In this method, the waste heat from the power plant can be utilized for the first water production method, while the generated electricity is utilized for the second. The key characteristics of these methods as reported by the world health organization (WHO), 2007 [22] and are summarized in Table 1. 
Table 1. Principal characteristics of different desalination processes.

\begin{tabular}{|c|c|c|c|}
\hline \multirow{2}{*}{ Characteristics } & \multicolumn{3}{|c|}{ Type of Process } \\
\hline & Phase Change & Non-Phase Change & Hybrid \\
\hline Nature & Thermal process & Pressure/concentration driven & Thermal + membrane \\
\hline Membrane pore size & - & $0.1-3.5 \mathrm{~nm}$ & $0.2-0.6 \mathrm{um}$ \\
\hline Feed temperature & $60-120^{\circ} \mathrm{C}$ & $<45^{\circ} \mathrm{C}$ & $40-80{ }^{\circ} \mathrm{C}$ \\
\hline $\begin{array}{l}\text { Driving force for } \\
\text { separation }\end{array}$ & $\begin{array}{c}\text { Temperature and } \\
\text { concentration gradient }\end{array}$ & $\begin{array}{l}\text { Concentration and } \\
\text { pressure gradient }\end{array}$ & $\begin{array}{c}\text { Temperature and } \\
\text { concentration gradient }\end{array}$ \\
\hline Energy source & Thermal and mechanical & Mechanical and/or electrical & Thermal and mechanical \\
\hline Form of energy & $\begin{array}{l}\text { Steam, low-grade heat, } \\
\text { or waste heat and some } \\
\text { mechanical energy } \\
\text { of pumping }\end{array}$ & $\begin{array}{l}\text { Requires prime quality } \\
\text { mechanical/electrical energy } \\
\text { derived from fossil fuels or } \\
\text { renewable sources }\end{array}$ & $\begin{array}{c}\text { Low-grade heat sources } \\
\text { or renewable energy } \\
\text { sources }\end{array}$ \\
\hline Product quality & $\begin{array}{l}\text { High quality distillate } \\
\text { with TDS }<20 \text { ppm }\end{array}$ & $\begin{array}{l}\text { Potable water quality } \\
\text { TDS }<500 \text { ppm }\end{array}$ & $\begin{array}{l}\text { High quality distillate } \\
\text { with TDS } 20-500 \text { ppm }\end{array}$ \\
\hline
\end{tabular}

Due to the remote and isolated nature of King Island encircled by the ocean, a desalination plant would be an appropriate solution to secure freshwater demand for the residents of the island. The capacity of the proposed desalination plant should sufficiently meet all domestic/nondomestic freshwater for the population of the island presently and in the next 25-year lifespan of the project. Based on Australia's population growth rate (0.3\% per annum) [8], we estimated the population of the island in 25 years would approximately be 1740 persons. The calculated water demand for this population based on the Tasmanian average daily water usage is equal to 4 ML per day [25]. All financial parameters, interest rates, council fees, and tax rates are extracted from credible technical and government reports $[12,26,27]$ and applied accordingly. These inputs are used in DEEP to model the financial logistics for different desalination technologies. Table 2 shows the main variables used in DEEP models. Figure 4 illustrates the cost components and the overall cost for the three primary and two hybrid desalination technologies developed to produce $4 \mathrm{ML} /$ day freshwater for the residents of King Island. This cost estimate is based on typical grid-connected desalination and before any integration with renewable sources. The desalination plant site is carefully chosen to reduce trenching, piping, and water transport costs. This site is the nearest to the main population city (Currie) and also to the sea-shore for effective feedwater delivery and also for brine discharge. It is well-established that SMF and MED would be economic candidates for very large-scale desalination process, but for small-scale desalination (i.e., $4 \mathrm{ML} /$ day), the $\mathrm{RO}$ would prevail. Figure 4 clearly demonstrates that the $\mathrm{RO}$ plant shows the lowest cost of water production compared to other options. This technology is the most cost-effective due to its low energy consumption and quick response at start-up and shutdown compared to thermal processes. It is noteworthy that an $\mathrm{RO}$ desalination plant can easily be operated by electric energy and, therefore, solar PV would be ideal candidate for electric power production. Both solar PV and $\mathrm{RO}$ units are modular and scalable to accurately meet the energy and water demand, respectively. Hybrid options can be derived based on the combination ratio between $\mathrm{RO}$ and thermal processes. Larger portions for thermal technologies would increase the heat portion and subsequently drive the overall cost higher. We built the hybrid models based on $50 \%$ contribution from each technology as presented in Figure 4. 
Table 2. The main variables employed in DEEP models.

\begin{tabular}{cccc}
\hline Parameter & Value & Parameter & Value \\
\hline Power source & Coal & Feed pressure & $64 \mathrm{bars}$ \\
Construction time & 24 months & Daily water capacity & $4000 \mathrm{~kL} /$ day \\
Plant lifetime & 25 years & Thermal utilization & $27 \%$ \\
Tax rate & $30 \%$ & Thermal output & $50 \mathrm{MWt}$ \\
Interest rate & $7 \%$ & Feed salinity & $35,000 \mathrm{ppm}$ \\
OPEX cost & $0.27-0.34 \$ / \mathrm{kL} *$ & Feed inlet temperature & $19^{\circ} \mathrm{C}$ \\
Power cost & $83.2 \$ / \mathrm{MWh}$ & Specific power use & $3.34 \mathrm{kWh} / \mathrm{kL}$ \\
\hline
\end{tabular}

* This range represents the varying cost of OPEX which is dependent on the water production, as each plant is sized to a different daily maximum production.

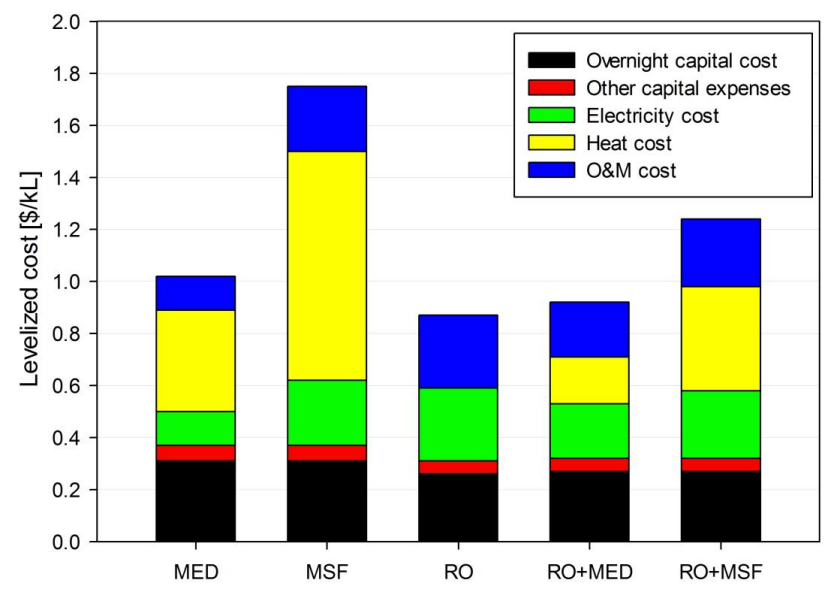

Figure 4. The cost comparison of different desalination technologies as calculated for $4 \mathrm{ML} /$ day freshwater delivery to King Island. The two hybrid plants are modelled at $50 \%$ capacity for each desalination technology.

\subsection{Renewable Energy Options}

In King Island, because of a low population density and poor infrastructure for freshwater and electricity transmission/distribution, renewable energy for desalination is a favourable option in both the short-term and long-term. Enormous research for integrating renewable power sources with various desalination technologies has been conducted $[28,29]$ It is well-established that solar energy is the most promising application with a significant contribution for sustainability [30]. Similarly, wind turbines are another sustainable approach for energy production. The transient nature of wind kinetics is different to that of solar energy. Wind turbines, if well-designed, may provide adequate energy in night times and in winter when solar energy is insufficient. A good combination of these two energy sources may better match the dynamic energy demand of RO desalination plant that is mainly governed by freshwater withdrawal and consumers' lifestyle. Freshwater demand not only fluctuates on an hourly basis, but also responds to climate variation and seasonal deviation. Dry and wet seasons also impact the freshwater withdrawal rates. In this study, we have incorporated two representative profiles that reflect on the hourly and seasonal load variation factors. These hourly and monthly water consumption profiles are based on credible water consumption forecasting studies [31,32]. As shown in Figure 5A for average daily profile, freshwater consumption is minimum during early hours of the day, peaking at morning times due to morning showers, toilets, breakfast, etc. Then water consumption rates decrease in midday limited to typical household duties (e.g., cooking, cloth washing, etc.), and then rise in the evening because of night showers before being declined to their lowest after midnight. Figure 5B shows water consumption profile reflecting monthly variation. Notably, water consumption drops during winter times because of less demand for gardening and irrigation and also reflecting moderate climate and cold ambient temperatures. The desalination plant must be equipped to meet 
water demand at all times, particularly in those peak hours and throughout the year. The solar field, wind farm, desalination capacity, standby units, pumps, and energy/water storage must be well-scaled to sufficiently meet freshwater demand at all times.
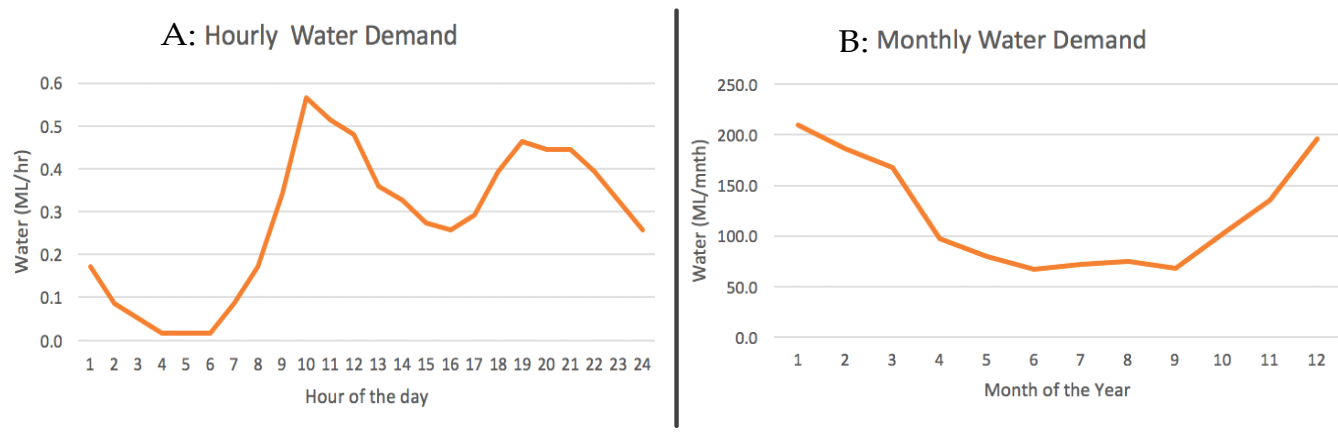

Figure 5. Freshwater consumption profile on (A) hourly (the data is plotted for 1 January); and (B) monthly basis.

To compare energy and water storage compatible with different renewable energy sources, four potential scenarios are considered. The objective of this comparison is to determine the most feasible option that can sufficiently meet the variable load at all times and at the lowest cost. These four scenarios are described above and depicted in Figure 6. Each of the symbols used for solar PV field, wind turbine, batteries, inverters, $\mathrm{RO}$ units, and water storage tanks are scaled to a particular capacity as outlined in the legend. The energy, freshwater, feed/brine water, and inactive streams also clarify the operation schemes in day and night modes. In Scenario 1, the solar PV field is sized to meet instant water load in day times and store excess electricity in a supplementary battery set. The inverters are also sized to convert the DC current at the PV outlet to AC current, usable by the pumps to bring the feed water pressure to the design point. As the desalination plant is always available to work on-demand, the design capacity should be able to meet the highest demand (worst case), although most of the times, it only needs to operate on partial load. This arrangement over-sizes the solar PV field, invertors, and battery storage capacity accordingly, but comparatively lowers the size of RO desalination plant. In Scenario 2, the batteries are eliminated but the desalination plant capacity is increased to produce more water during the day and shutdown at night times. The adequate sizing of water storage tanks, that store excess water, is able to control demand; extra water produced in the summer season helps in responding to demand in the winter without the need for oversizing solar PV field to respond to winter energy deficits. In Scenario 3, this concept is further elaborated by reducing solar PV field and introducing $2 \times 2.5 \mathrm{MW}$ wind turbines. The benefit of wind turbines is in providing energy, although intermittent, when most needed (most valued in night times and winter season). This combination is expected to decrease solar PV field size and water storage capacity as of Scenario 2. In Scenario 4, the role of wind contribution is doubled by employing $4 \times 2.5 \mathrm{MW}$ wind turbines. Although this scenario will increase the cost of wind farm, but it will also significantly reduce the solar PV field and water storage capacity. The main economic assumptions adopted for these four scenarios are presented in Table 3.

Table 3. The main variables employed in SAM models.

\begin{tabular}{cccccc}
\hline Parameter & Cost & Reference & Parameter & Cost & Reference \\
\hline Solar Module & $0.71 \$ / \mathrm{W}_{\mathrm{dc}}$ & {$[33]$} & Energy OPEX & $20 \$ / \mathrm{kW}$-year & {$[13]$} \\
Solar Invertor & $0.21 \$ / \mathrm{W}_{\mathrm{dc}}$ & {$[33]$} & Federal Tax & $30 \%$ & {$[27]$} \\
Battery & $0.6 \mathrm{M} \$ / \mathrm{MWh}$ & {$[13]$} & State Tax & $6.1 \%$ & {$[34]$} \\
Wind Turbine & $3.915 \mathrm{M} \$ /$ turbine & {$[13]$} & Inflation & $1.7 \%$ & {$[35]$} \\
Water Storage Tank & $50 \$ / \mathrm{kL}$ & {$[36]$} & Property Tax & $1.55 \%$ & {$[37]$} \\
Land Cost & $18,000 \$ /$ acre & {$[38]$} & Interest Rate & $7 \%$ & {$[26]$} \\
\hline
\end{tabular}




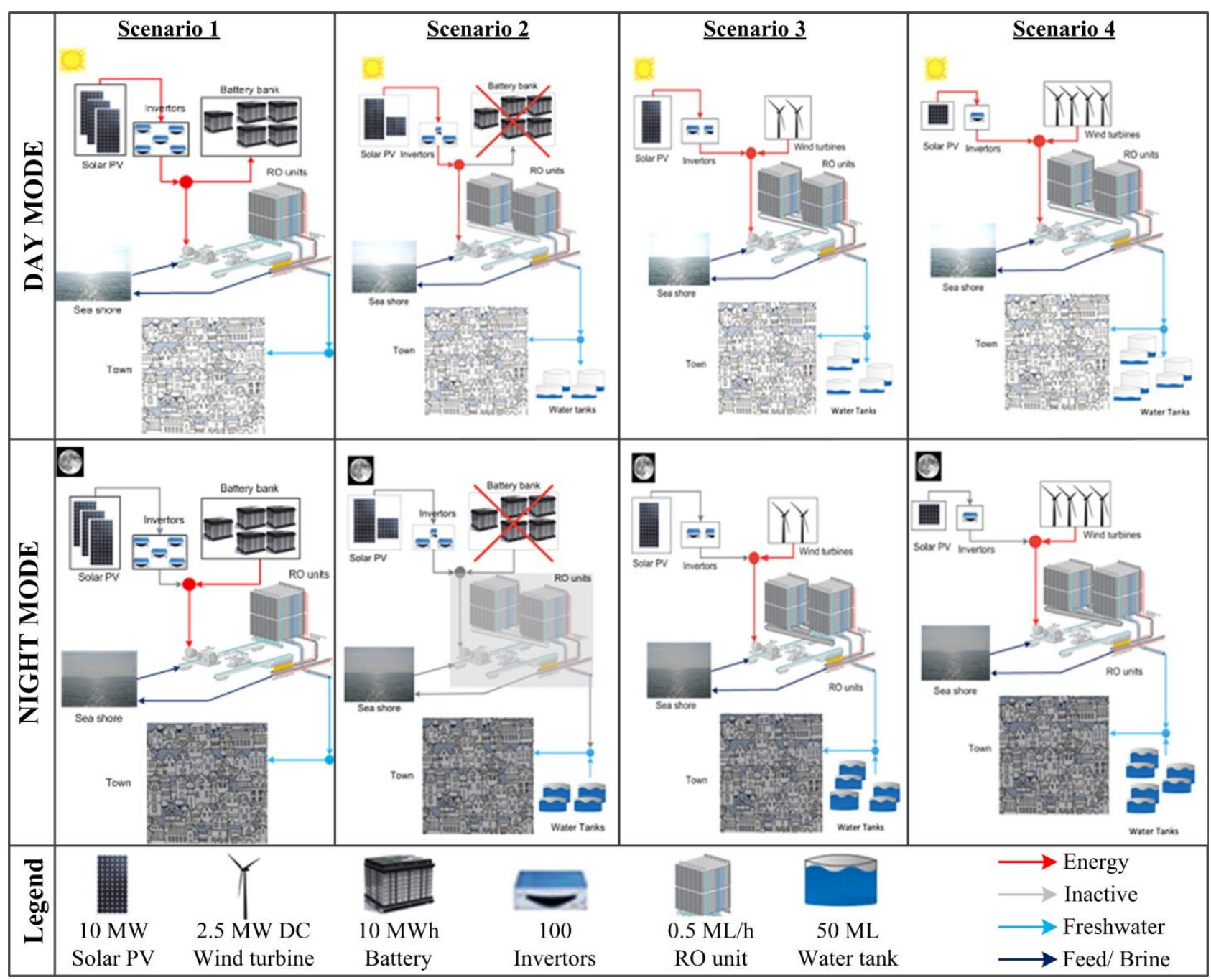

Figure 6. Illustrations of the day and night operation for each scenario. The capacity/size of each unit is demonstrated as in the legend (i.e., five tanks in Scenario 3 equal to 250 ML capacity). 


\section{Results and Discussion}

\subsection{Scenario 1: Solar PV + Battery Storage + RO Units}

This scenario represents a conventional solar PV power production supplemented by energy storage. The optimal size of the solar PV field is found to be $30 \mathrm{MW}_{\mathrm{dc}}$ and the required battery size is $50 \mathrm{MWh}$. The maximum daily water production is $6.76 \mathrm{ML}$. The total capital cost for this scenario is $\$ 113.1 \mathrm{M}$ and the levelized water cost of water is $4.15 \$ / \mathrm{kL}$. The intensity of generated electric power, as seen in Figure 7-Scenario 1, is proportional to the solar irradiation data for King Island. It shows more intense power production in summer compared to winter. It is evident that the solar PV field is oversized to meet diurnal energy demand for desalination and divert the excess energy to the battery storage. The intensity of stored electricity, shown in Figure 8-Scenario 1, also declines in winter months because of less power supplied by solar PV field. However, it is sufficient to meet most of the load for night time operation when needed. It should be noted that there is a number of times throughout the year when the battery storage is completely drained which requires extra measures (e.g., connect to the available local power sources or arranging another external energy source) to maintain the fluidity of freshwater production. Further oversizing of the solar PV field or battery storage to overcome power shortage in these few deficit hours is found to be very costly.

\subsection{Scenario 2: Solar $P V+R O$ Units + Water Storage Tanks}

In this scenario, the costly battery set is eliminated and substituted by water storage. Water storage tanks are simple, less expensive, and easier to install and maintain. Their lifetime is longer than batteries and do not endure self-discharge. Freshwater can be frequently charged at the top and discharged from the bottom of the tank to maintain healthy water circulation. Adequate sizing and integration of the trio (solar PV field + desalination plant + water storage tanks) can be more effective in utilizing excessive surges of solar irradiation, and therefore, a smaller solar PV field with larger desalination plant can sufficiently meet the load. Furthermore, a larger desalination capacity interpreted in less operation times (only when solar is available) would eventually increase the lifespan of the RO units. In this scenario, the optimal solar field is found to be $13 \mathrm{MW}$ and the total water tank size is $172 \mathrm{ML}$. At any point throughout the year, $6.94 \mathrm{ML}$ is the maximum daily produced water. The total capital cost for this scenario is $\$ 50.7 \mathrm{M}$ and the levelized water cost is $1.87 \mathrm{\$} / \mathrm{kL}$ which is $55 \%$ less expensive than Scenario 1 . The availability of water storage tanks is a very stabilizing factor. Assuming tank capacity of approximately $50 \mathrm{ML}$, four tanks would be required, although only two tanks will be in use for a majority of the year. We found that solar PV field does not need to be oversized to meet peak hours. Consequently, the solar field size (PV units, invertors, and land size) in this scenario is reduced to approximately $43 \%$ of that of Scenario 1 which resulted in significantly improved economics. The generated electric power followed the same pattern of Scenario 1 but to a lesser extent (Figure 7-Scenario 2). The cumulative water storage in the storage tanks is presented in Figure 8-Scenario 2. It is assumed that water storage tanks were almost half-full at the beginning of the project to avoid oversizing of water storage tanks. This assumption is reasonable and achievable by supplying initial freshwater (approximately $120 \mathrm{ML}$ ) from the current water resources, then the water generation process will be totally independent. The margin of stored water is the lowest in autumn (Figure 8-Scenario 2), which is most likely not adequate in meeting possible excess withdrawals. The pattern of cumulative water in the storage tanks almost flattens at winter times where water consumption and energy production rates are minimal. 

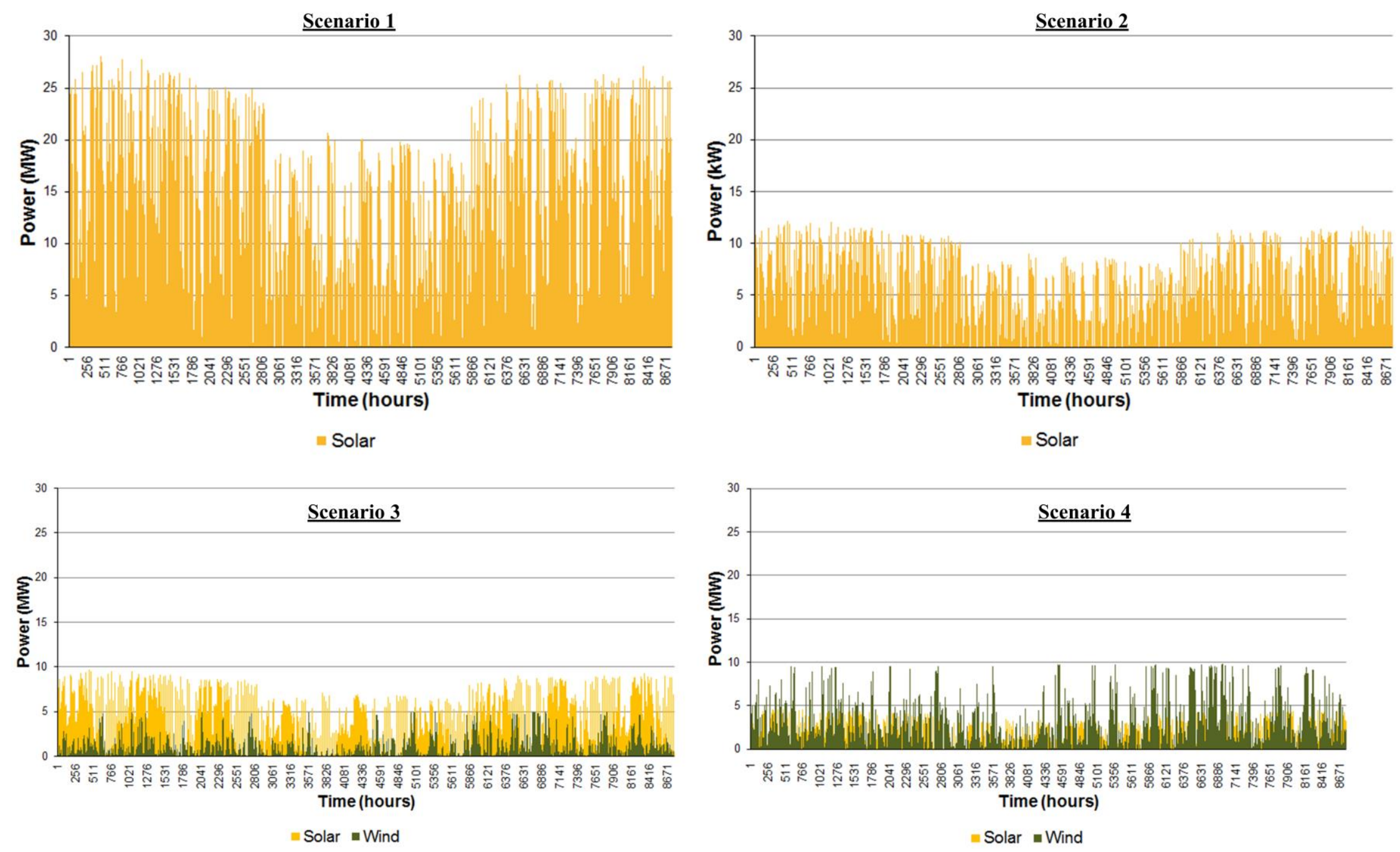

Figure 7. Hourly electric power production at each scenario. 

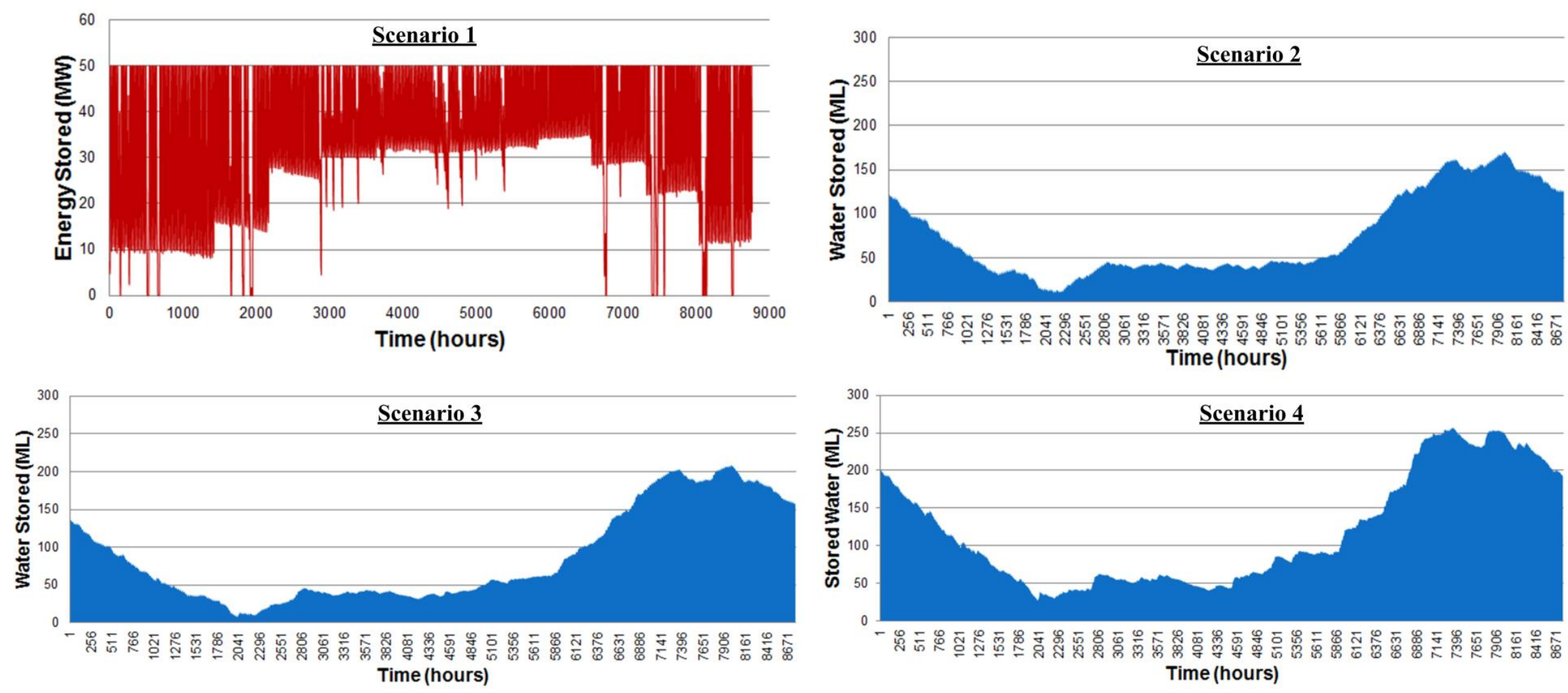

Figure 8. Cumulative storage/Capacities for each scenario. 


\subsection{Scenario 3: Solar PV + Two Wind Turbines + RO Units + Water Storage Tanks}

This scenario elaborates on the same logics of Scenario 2 but with the addition of the wind contribution. The required solar field size is reduced to $10.3 \mathrm{MW}_{\mathrm{dc}}$, combined with a wind farm size of $5 \mathrm{MW}$, and the required water tank capacity increased to $210 \mathrm{ML}$. In comparison to Scenario 2 and by integrating the production of two wind turbines (Fuhrlander FL 2500_100), solar field size is reduced by $20.8 \%$, while water storage tank capacity is increased by $22.1 \%$. The freshwater pre-fill in this scenario is approximately $135 \mathrm{ML}$. This integration in power generation has also increased instant water production in diurnal times and allowed for partial night operation in the desalination plant upon power availability from the wind farm and instant demand for freshwater. The maximum daily production increased to $10.6 \mathrm{ML}$ which increased the desalination plant size by almost $52 \%$. The capital cost for this scenario is $\$ 58.7 \mathrm{M}$ and the levelized water cost is $2.17 \$ / \mathrm{kL}$ which is $16 \%$ more expensive than Scenario 2. The combined power generation from solar and wind sources, as shown in Figure 7-Scenario 3, shows a more consistent dispersion throughout the year compared to the previous scenarios. This is because the wind power generation is more random and partially able to fill up the gaps in the solar energy production profile. A seasonal trend is still apparent, but at less magnitude than previous scenarios. The cumulative water storage (Figure 8-Scenario 3) almost follows a similar trend of Scenario 2. This scenario will require approximately five tanks (50 ML capacity), but as before, only 2 will be in use for a majority of the year. Slightly larger water storage in this scenario is most likely due to capture and store high water productivity in those simultaneous peak solar and wind times throughout the year. By analyzing the wind profile, it is seen that during the colder months when solar power output is significantly decreased, wind power output was not able to completely fill the gaps as a substitution for power demand, and so cannot fully accommodate for the lack of solar power output at that period of the year. The next scenario is proposed to double the power production from the wind farm and proportionally reduce the solar field size.

\subsection{Scenario 4: Solar PV + Four Wind Turbines + RO Units + Water Storage Tanks}

This scenario elaborates on the same logics of Scenario 3, but doubles the wind farm size. In this option, the optimized solar PV field is reduced to $5 \mathrm{MW}_{\mathrm{dc}}$, while wind farm capacity is doubled to $10 \mathrm{MW}$, while the required water tanks capacity is increased to $257 \mathrm{ML}$. In comparison to Scenario 3, solar field size is reduced by $51.4 \%$, while water storage capacity increased by $22.3 \%$. The freshwater pre-fill for this scenario is set to $200 \mathrm{ML}$. The maximum daily water production is $15.93 \mathrm{ML}$ increasing the desalination plant capacity of Scenario 3 by almost $50 \%$. The capital cost for this scenario increased to $\$ 62.9 \mathrm{M}$ and the levelized water cost is $2.49 \$ / \mathrm{kL}$, which is $14.7 \%$ more expensive than Scenario 3 . The combined power generation from solar and wind sources, as shown in Figure 7-Scenario 4, has an even better dispersion throughout the year compared to the Scenario 3. Wind power profile is the dominant player is this scenario, and together with solar profile, shows a denser power output and much less gaps. The seasonal trend of the overall power production almost disappeared which resulted in more homogeneous water production and allowed for massive reduction in the solar field size. The cumulative water storage (Figure 8-Scenario 4) shows a more comfortable cumulative profile with a comparatively sufficient margin in the autumn season. This, however, may provide even more room for better tuning and size reduction in the solar PV field and/or water storage tanks. This scenario will require six tanks (50 ML capacity), where three of them will be in use for a majority of the year. In this scenario, the water pre-fill would be almost $200 \mathrm{ML}$ (Figure 8-Scenario 4) to avoid oversizing of the water storage tanks.

\subsection{Scenario Comparison}

Overall, this case-study highlights the need for a rigorous assessment of the energy end-use particularly for renewable applications. Energy storage options (Figure 1) have enormous benefits and also drawbacks. However for these high investment decisions, the choice of the right EST(s) 
should be application and/or location specific. As for desalination, water storage scenarios prevail on energy storage for off-grid desalination process powered by renewable resources. Instant water production by desalination and storing excess water in large and sanitary storage tanks found to be more convenient and less-expensive option. The sizing of solar PV field in the first scenario (energy storage) is found more sensitive to load variation which demanded a relatively large solar field and battery banks to minimize the energy drains in those peak-load hours. By moving to water storage scenarios (scenarios 2-4), convenient size reductions in the solar PV field were achieved.

Several complications do exist between proposed scenarios where each show interesting characteristics. The power production in the first two scenarios is sourced out from the solar PV field only, therefore, it is found the most productive day was on 19 January resulting in $6.76 \mathrm{ML}$ water production for Scenario 1 and 6.94 ML for Scenario 2, whereas the most productive day in scenarios 3 and 4 were on 20 November resulting in 10.6 ML water production for Scenario 3 and 15.93 ML for Scenario 4. These maximum daily production rates are the determining factors for sizing the desalination plants in each scenario. It is obvious that increased solar/wind electric power output (without having energy storage as in Scenario 1) would require more pumps and RO modules to produce more water. Therefore, these daily water production caps are used in determining the desalination plant capacity and consequently the cost. This also highlights a complex but sensible trade-off between the main cost components (e.g., solar field, energy storage, wind farm, desalination plant, and water storage) in these representative four scenarios which may entail in-depth techno-economic analysis. These energy/water production capacities are calculated at design point only and exclude extra margins. However in the design, it is always recommended that a reasonable safety margin should be considered to account for sudden over-drawings in water or deficits in power production. The safety margin is directly proportional to the water pre-fill amount at the simulation startup. This value is adjusted based on an optimization criteria defined as the lowest storage capacity that cause no water spill and no water deficit at any time step. For the current settings, we investigated the safety margin for the three scenario as in Table 4.

Table 4. Safety margin for water storage scenarios.

\begin{tabular}{ccccc}
\hline Scenario & $\begin{array}{c}\text { Water Pre-Fill in } \\
\text { Water Tanks (ML) }\end{array}$ & $\begin{array}{c}\text { Lowest Water } \\
\text { Margin (ML) }\end{array}$ & At Hour of the Year & Sufficient Water for * \\
\hline 2 & 120 & 10.6 & 8 am, 30 Mar & 2.6 days \\
3 & 140 & 12.7 & 8 am, 25 Mar & 3.2 days \\
4 & 200 & 27.1 & 2 am, 25 Mar & 6.8 days \\
\hline
\end{tabular}

* This calculation is based on an average of $4 \mathrm{ML} /$ day water demand for the island's population.

Although increasing the water pre-fill can improve safety margin and water accessibility, but that would be associated with extra cost and/or water surplus. For reliable water production, we found this safety margin was most satisfactory in Scenario 4 caused by intense energy production from both energy sources (solar PV and wind) and also sufficient desalination plant capacity. The cost components are illustrated in Table 5 for comparison between the four scenarios. Scenario 1 is found comparatively unfeasible because of the hefty cost of a very large solar PV field and associated battery storage (Table 5). Among the three water storage scenarios, Scenario 4 shows more consistent energy/water profiles that can effectively harmonize the transient nature of energy sources with the water consumption dynamics. Despite the very low cost of the solar PV field in Scenario 4, the capital cost surges because of the larger wind farm and oversized desalination and water storage capacities. Economically, Scenario 2 shows the lowest capital investment and subsequently the less expensive as levelized per $\mathrm{kL}$ of water production. Scenario 2 shows a significant cost reduction compared with Scenario 1 and also does not bear over sizing of desalination plant and water storage tanks (Table 5). We found Scenario 2 trades-off the major cost components relatively better and slightly improves the economics in comparison to scenarios 3 and 4 . However, any major disturbance in one or more of 
the cost components would certainly change the game. For example, dearer land cost/availability would have significant impact on scenarios 1 and 2 compared to scenarios 3 and 4 . In short, this study emphasizes the significance of customizing smart-solutions for the energy and water portfolios and on a case-by-case basis.

Table 5. Results comparison for all scenarios.

\begin{tabular}{ccccc}
\hline Key Parameters & Scenario 1 & Scenario 2 & Scenario 3 & Scenario 4 \\
\hline Solar Field Size (MW) & 30 & 13 & 10.3 & 5 \\
Wind Turbine Power (MW) & - & - & 5 & 10 \\
Battery Size (MWh) & 50 & - & - & - \\
Tank Size (ML) & - & 172 & 210 & 257 \\
Max daily Water Production (ML/day) & 6.76 & 6.94 & 10.6 & 15.93 \\
Desalination Plant Cost (M\$) & 9 & 10 & 15 & 22 \\
Water Tank Cost (M\$) & - & 8.6 & 10.5 & 12.8 \\
Solar Module Cost (M\$) & 21.3 & 9.2 & 7.3 & 3.5 \\
Solar Invertor Cost (M\$) & 6.3 & 2.7 & 2.2 & 1 \\
Battery Cost (M\$) & 30 & - & - & - \\
Wind Turbine Cost (M\$) & - & - & 7.8 & 15.7 \\
Overhead/Installation Cost (M\$) & 44 & 19.2 & 15.1 & 7.5 \\
Land Costs (M\$) & 2.5 & 1 & 0.8 & 0.4 \\
Total Capital Cost (M\$) & $\mathbf{1 1 3 . 1}$ & $\mathbf{5 0 . 7}$ & $\mathbf{5 8 . 7}$ & $\mathbf{6 2 . 9}$ \\
CAPEX levelized Water Cost (\$/kL) & 3.39 & 1.39 & 1.59 & 1.74 \\
OPEX for energy infrastructure (\$/kL) & 0.45 & 0.18 & 0.14 & 0.07 \\
OPEX for water infrastructure (\$/kL) & 0.31 & 0.30 & 0.44 & 0.68 \\
Overall Levelized Water Cost (\$/kL) & $\mathbf{4 . 1 5}$ & $\mathbf{1 . 8 7}$ & $\mathbf{2 . 1 7}$ & $\mathbf{2 . 4 9}$ \\
\hline
\end{tabular}

\section{Conclusions}

This study highlighted the implications of integrating energy storage with renewable energy sources. We argued that the end-use application would certainly influence the selection of energy storage and only if needed. For renewable-driven off-grid desalination process, it was demonstrated that energy storage is not an optimal option in comparison with product (water) storage. It was also proven that a combination of two or more renewable energy sources would harmonize the power productivity and reduce the effect of intermittency. We proposed four scenarios of water production in the King Island case-study. The transient conditions of energy sources (solar and wind), and water consumption dynamics are taken into consideration in the sizing of the solar PV field, energy storage, desalination capacity, and water storage tanks. It was found that a $13 \mathrm{MW}$ solar PV field can be sufficient to instantly run a proportional RO desalination plant and generate immediate freshwater in diurnal times without the need for energy storage (Scenario 2). The excess generated water can be stored in designated storage tanks to meet the load in those solar deficit times. It was demonstrated that integrating a well-sized solar PV with wind power production shows more consistent energy/water profiles that harmonize the transient nature of energy sources with the water consumption dynamics (scenarios 3 and 4), but that would have a trivial economic penalties caused by larger desalination and water storage capacities.

Acknowledgments: The authors wish to thank the instructors and students who participated in the unit of study "Sustainable Design" (ENGG5202) at the University of Sydney in 2015 for trialing this case study in their tutorials. The authors acknowledge Mohammad Al Mansour from KSU for contributing to the initial assessment during his short visit to the University of Sydney in 2015. Preliminary results from this study were presented at the Energy Future Conference held in Sydney Australia 4-6 July 2016.

Author Contributions: Aya Tafech checked the data, developed the models, and presented the results. Dia Milani interpreted, validated, and drafted the results, composed the manuscript, and corresponded to the journal's editorial board. Ali Abbas directed the project and edited the manuscript.

Conflicts of Interest: The authors declare no conflict of interest. 


\section{Abbreviations}

The following abbreviations are used in this manuscript:

$\begin{array}{ll}\text { CAPEX } & \text { Capital cost } \\ \text { DEEP } & \text { Desalination Economic Evaluation Program } \\ \text { ED } & \text { Electro-dialysis } \\ \text { EST } & \text { Energy storage technology } \\ \text { RET } & \text { Renewable energy technologies } \\ \text { MED } & \text { Multiple effect distillation } \\ \text { MSF } & \text { Multi-stage flash } \\ \text { MVC } & \text { Mechanical vapor compression } \\ \text { OPEX } & \text { Operation and maintenance cost } \\ \text { RO } & \text { Reverse osmosis } \\ \text { SAM } & \text { System Advisor Model } \\ \text { TDS } & \text { Total dissolved solids } \\ \text { TVC } & \text { Thermal vapor compression }\end{array}$

\section{References}

1. REN21. Renewables 2016 Global Status Report; REN21 Secretariat: Paris; ISBN: 978-3-9818107-0-7. 2016. Available online: http://www.ren21.net/status-of-renewables/global-status-report/ (accessed on 14 August 2016).

2. Chen, H.; Cong, T.N.; Yang, W.; Tan, C.; Li, Y.; Ding, Y. Progress in electrical energy storage system: A critical review. Prog. Nat. Sci. 2009, 19, 291-312. [CrossRef]

3. Evans, A.; Strezov, V.; Evans, T.J. Assessment of utility energy storage options for increased renewable energy penetration. Renew. Sustain. Energy Rev. 2012, 16, 4141-4147. [CrossRef]

4. Sandia National Laboratories. DOE Global Energy Storage Database. Available online: http://www. energystorageexchange.org/projects (accessed on 13 August 2016).

5. Walawalkar, R.; Apt, J. Market Analysis of Emerging Electric Energy Storage Systems; National Energy Technology Laboratory: Pittsburgh, PA, USA, 2008; pp. 1-118.

6. Tsoutsos, T.; Frantzeskaki, N.; Gekas, V. Environmental impacts from the solar energy technologies. Energy Policy 2005, 33, 289-296. [CrossRef]

7. Gallo, A.B.; Simões-Moreira, J.R.; Costa, H.K.; Santos, M.M.; dos Santos, E.M. Energy storage in the energy transition context: A technology review. Renew. Sustain. Energy Rev. 2016, 65, 800-822. [CrossRef]

8. Economics Analysis Unit. Regional Population Growth; Tasmanian Government: Tasmania, Australia, 2016.

9. Meter, J.V. Experimental invenstigation of a printed circuit heat exchanger using supercritical carbon dioxide and water as heat transfer media. In Department of Mechanical and Nuclear Engineering College of Engineering; Kansas State University: Manhattan, KS, USA, 2006.

10. Searle, D. Water Quality and Stream Condition on King Island 2004-2008; Cradle Coast Natural Resource Management: Launceston, Australia, 2010.

11. Milne, J.; Finzel, E. King Island Natural Resource Management Strategy 2010 to 2020; King Island Natural Resource Management Group: Tasmania, Australia, 2010.

12. International Atomic Energy Agency (IAEA). Desalination Economic Evaluation Program; IAEA: Vienna, Austria, 2015.

13. NREL. System Advisor Model; National Renewable Energy Laboratory: Golden, CO, USA, 2014.

14. Mezher, T.; Fath, H.; Abbas, Z.; Khaled, A. Techno-Economic Assessment and Environmental Impacts of Desalination Technologies. Desalination 2011, 266, 263-273. [CrossRef]

15. Raluy, G.; Serra, L.; Uche, J. Life cycle assessment of MSF, MED and RO desalination technologies. Energy 2006, 31, 2361-2372. [CrossRef]

16. Van der Bruggen, B.; Vandecasteele, C. Distillation vs. membrane filtration: Overview of process evolutions in seawater desalination. Desalination 2002, 143, 207-218. [CrossRef]

17. Ihm, S.; Al-Najdi, O.Y.; Hamed, O.A.; Jun, G.; Chung, H. Energy cost comparison between MSF, MED and SWRO: Case studies for dual purpose plants. Desalination 2016, 397, 116-125. [CrossRef]

18. Association, I.D. Desalination by the Numbers. 2016. Available online: http://idadesal.org/desalination101/desalination-by-the-numbers / (accessed on 19 July 2016).

19. Voutchkov, N. Desalination Engineering: Planning and Design; McGraw Hill Professional: New York, NY, USA, 2012. 
20. Ghaffour, N.; Missimer, T.M.; Amy, G.L. Combined desalination, water reuse, and aquifer storage and recovery to meet water supply demands in the GCC/MENA region. Desalination Water Treat. 2013, 51, 38-43. [CrossRef]

21. Shahabi, M.P.; McHugh, A.; Anda, M.; Ho, G. Comparative economic and environmental assessments of centralised and decentralised seawater desalination options. Desalination 2015, 376, 25-34. [CrossRef]

22. WHO. Desalination for Safe Water Supply-Guidance for the Health and Environmental Aspects Applicable to Desalination; World Health Organization: Geneva, Switzerland, 2007.

23. American Membrane Technology Association (AMTA). Water Desalination Processes; AMTA: Stuart, FL, USA, 2007.

24. Mabrouk, A.N.; Fath, H.E. Technoeconomic study of a novel integrated thermal MSF-MED desalination technology. Desalination 2015, 371, 115-125. [CrossRef]

25. ABS. Water Account Australia 2010-11. 2013. Available online: http://www.abs.gov.au/AUSSTATS/abs@ .nsf/Lookup/4610.0Main+Features402010-11\#Tasmania (accessed on 15 June 2016).

26. Parliment of Australia. Business Interest Rates. Available online: http://www.aph.gov.au/About_ Parliament/Parliamentary_Departments/Parliamentary_Library/pubs/MSB/feature/FeatureBIRFeb08 (accessed on 23 June 2016).

27. Australian Taxation Office. Company Tax Rates. Available online: https://www.ato.gov.au/rates/company-tax/ (accessed on 23 June 2016).

28. Ghaffour, N.; Bundschuh, J.; Mahmoudi, H.; Goosen, M.F. Renewable energy-driven desalination technologies: A comprehensive review on challenges and potential applications of integrated systems. Desalination 2015, 356, 94-114. [CrossRef]

29. Byrne, P.; Fournaison, L.; Delahaye, A.; Ouméziane, Y.A.; Serres, L.; Loulergue, P.; Szymczyk, A.; Mugnier, D.; Malaval, J.L.; Bourdais, R.; Guéguen, H. A review on the coupling of cooling, desalination and solar photovoltaic systems. Renew. Sustain. Energy Rev. 2015, 47, 703-717. [CrossRef]

30. Delyannis, E. Historic background of desalination and renewable energies. Sol. Energy 2003, 75, 357-366. [CrossRef]

31. Gato, S. Forecasting urban residential water demand. In School of Civil, Environmental and Chemical Engineering Science, Engineering and Training; RMIT University: Melbourne, Australia, 2006; p. 298.

32. Athuraliya, A.; Roberts, P.; Brown, A. Residential water use study. Yarra Val. Future Water 2012, 2, 1-44.

33. Solar Choice. Commerical Solar PV Price Index: March 2016. 2016. Available online: http:/ /www.solarchoice. net.au/blog/news/commercial-solar-pv-system-prices-march-2016-300316 (accessed on 30 June 2016).

34. Tasmanian Government Department of Treasury and Finance. Rates and Thresholds. 2016. Available online: http:/ /www.sro.tas.gov.au/domino/dtf/SROWebsite.nsf/0/9C229965D02EBC2ECA2575990022229E? OpenDocument\&menuitem=Payroll\%20Tax (accessed on 3 July 2016).

35. Reserve Bank of Australia. Inflation. 2016. Available online: http://www.rba.gov.au (accessed on 3 July 2016).

36. Water Resources Management Division. Evaluation of Potable Water Storage Tanks in Newfoundland and Labrador and Their Effect on Drinking Water Quality; Government of Newfoundland and Labrador Department of Environment and Conservation: St. John's, NL, Canada, 2011.

37. Tasmanian Government Department of Treasury and Finance. Rates of Land Tax. 2016. Available online: http:/ / www.sro.tas.gov.au/landtax/rates (accessed on 7 July 2016).

38. Domain. 2016. Available online: http://www.domain.com.au/lot-5-south-road-nugara-king-island-tas7256-2012249133 (accessed on 25 July 2016).

(C) 2016 by the authors; licensee MDPI, Basel, Switzerland. This article is an open access article distributed under the terms and conditions of the Creative Commons Attribution (CC-BY) license (http://creativecommons.org/licenses/by/4.0/). 